\title{
FORMAÇÃO CONTINUADA DE PROFESSORES DA EDUCAÇÃO PROFISSIONAL: UMA EXPERIÊNCIA EM EAD.
}

\author{
SÃO PAULO/SP MAIO/2018
}

\author{
Eva Chow Belezia - CEETEPS - 2005.eva@gmail.com
}

\author{
Tipo: Relato de Experiência Inovadora (EI) \\ Categoria: Métodos e Tecnologias \\ Setor Educacional: EDUCAÇÃO MÉDIA E TECNOLÓGICA
}

\begin{abstract}
RESUMO
A formação continuada de professores é tema constantemente abordado no contexto educacional por pesquisadores e educadores como Nóvoa (2001), Perrenoud (2000) e Peterossi (2017) entre outros, acrescidos atualmente dos desafios da modalidade ensino a distância. O presente trabalho, uma narrativa reflexiva, se propõe a relatar uma experiência de formação continuada de professores da educação profissional na modalidade a distância, com foco nos aspectos da andragogia tendo em vista o público dos cursos técnicos modulares e do Ensino Técnico Integrado ao Médio EJA (ETIM-EJA), em sua grande maioria (mais de 70\%) com idade superior a 18 anos. A proposta desse curso também aplica os princípios da andragogia, uma vez que o público-alvo é constituído de professores, coordenadores e gestores das escolas técnicas do estado de São Paulo, todos eles com perfil semelhante aos alunos, isto é, adultos e trabalhadores em atividade. Assim, o artigo relata o curso de Pós-Graduação Aperfeiçoamento Ensino e Aprendizagem na Educação de Jovens e Adultos, desenvolvido pelo Centro Paula Souza, instituição que tem no ensino técnico e tecnológico públicos sua 'expertize' e é responsável por 222 escolas técnicas e 71 faculdades de tecnologia. A primeira edição do curso iniciou-se em 2013, estando agora em sua $7^{a}$ edição, sempre com oferta de 160 vagas por curso, embora o número de cursistas matriculados tenha na maior parte das ocasiões ultrapassado o número de vagas. 0 currículo foi organizado com 5 disciplinas, com cargas horárias de 40 horas, totalizando um curso de 200 horas, 40 delas presenciais e 160 a distância. Os resultados alcançados até o momento, do ponto de vista quantitativo, indicam a totalidade de 930 professores certificados ou $76 \%$ de aprovados, e do ponto de vista qualitativo, revelou-se um curso avaliado como muito bom e bom por mais de $90 \%$ dos cursistas, segundo os questionários de avaliação respondidos pelos cursistas de cada turma, no Google Drive.
\end{abstract}

Palavras-chave: Formação continuada; Ensino a distância; Andragogia; Educação profissional. 


\section{INTRODUÇÃO}

O Centro Paula Souza, autarquia de regime especial vinculada à Secretaria de Desenvolvimento Econômico, Ciência, Tecnologia e Inovação, é responsável pelos 150 cursos técnicos de nível médio, 74 cursos tecnológicos, além de cursos de Formação Inicial, Pós graduação, atualização técnica e tecnológica e extensão, oferecidos em suas 222 escolas técnicas e 71 faculdades de tecnologia.

A instituição promove, com o intuito de buscar constante melhoria na qualidade da educação profissional oferecida aos mais de 290 mil alunos, a capacitação e atualização de seu corpo docente, em um amplo programa de formação continuada em serviço, que vai de cursos rápidos de 40 horas a cursos de aperfeiçoamento de 180 a 200 horas, pós graduação latto sensu e especialização (360 horas), formação de professores (1000 horas) e pós-graduação stricto sensu, todos oferecidos nas modalidades presencial, semi presencial e à distância.

Considerando que mais de $70 \%$ dos alunos da Educação Profissional de Nível Médio estão caracterizados como adultos e jovens-adultos, ou seja, com mais de 18 anos, nos cursos modulares concomitantes ou subsequentes, e ainda que são oferecidos cursos de Ensino Técnico Integrado ao Médio na modalidade EJA (ETIM-EJA), faz-se necessário aprofundar os saberes docentes para os princípios da andragogia, com foco no adulto que traz em seu bojo experiências de vida, pessoais, sociais e profissionais.

Ao mesmo tempo, o curso ora apresentado constitui-se em um laboratório de vivências metodológicas, onde os cursistas são professores, portanto adultos com diversificadas experiências de vida pessoais, sociais e profissionais. Muitos desses professorescursistas são, inclusive, usuários primários da tecnologia, deparando-se pela primeira vez com os desafios de um curso à distância.

Este artigo objetiva descrever essa experiência.

\section{O CONTEXTO}

O Parecer CNE 02/2015 considera de relevância a melhoria na qualidade da educação a valorização dos educadores com o estabelecimento de metas como proporcionar a $50 \%$ dos professores de Educação Básica cursos de pós-graduação e garantir a formação continuada dos profissionais da educação em sua área de atuação. Vale reproduzir o explicitado no referido Parecer, em seu item 2.4- Formação continuada dos profissionais do magistério: 
A formação continuada compreende dimensões coletivas, organizacionais e profissionais, bem como o repensar do processo pedagógico, dos saberes e valores, e envolve atividades de extensão, grupos de estudos, reuniões pedagógicas, cursos, programas e ações para além da formação mínima exigida ao exercício do magistério na educação básica, tendo como principal finalidade a reflexão sobre a prática educacional e a busca de aperfeiçoamento técnico, pedagógico, ético e político do profissional docente (MEC-CNE. 2015).

São definidos pelo Conselho Nacional de Educação - CNE(2015) diversos níveis e modalidades de formação continuada: cursos de atualização, de extensão, de aperfeiçoamento (mínimo de 180 horas), especialização (mínimo de 360 horas), mestrado (acadêmico ou profissional) e doutorado.

Os cursos de especialização, foco deste artigo, visam ampliar os conhecimentos em determinadas disciplinas ou áreas, para profissionais em exercício profissional visando a melhoria e inovação em seu desempenho.

Em 2011 o Centro Paula Souza apresentou ao Ministério da Educação, com vistas ao Programa Brasil Profissionalizado[1], um projeto que contemplava duas dimensões para o ensino profissional: a atualização dos laboratórios e oficinas das etecs e a formação continuada dos professores e gestores.

Em relação à formação continuada, o programa era dividido em quatro sub-ações:

- Curso de Pós-Graduação Lato sensu - MBA em Gestão de Projetos e Processos Organizacionais (360 horas);

- Curso de Pós-Graduação Aperfeiçoamento - Ensino e Aprendizagem na Educação de Jovens e Adultos (200 horas);

- Programa Especial de Formação Pedagógica para Professores de Ensino Técnico de Nível Médio (360 horas)[2];

- Atualização Técnica dos professores dos Eixos Tecnológicos de EPT[3] (40 horas)

O projeto apresentado ao MEC resultou na assinatura do Convênio CPS/FNDE no 400012/2011, ainda vigente por prorrogação.

\section{O CURSO ENSINO E APRENDIZAGEM NA EDUCAÇÃO DE JOVENS E ADULTOS}

O curso Ensino e Aprendizagem na Educação de Jovens e Adultos é uma pós- 
graduação aperfeiçoamento com carga horária de 200 horas, sendo 40 horas presenciais e 160 horas desenvolvidas a distância, no ambiente virtual de aprendizagem do Moodle (http://moodle.cpscetec.cps.sp.gov.br/capacitacaopos_pbp/).

Foram aplicados no curso os princípios de andragogia, considerando as características específicas do público, profissionais da educação básica, principalmente do ensino médio e técnico, de instituições públicas municipais, estaduais e federais e também atuantes no sistema prisional do estado de São Paulo, com ampla troca de experiências de vida e profissionais.

Assim, as atividades foram planejadas e propostas com a finalidade de estimular estas trocas e também reflexões e debates, baseadas nas vivências cotidianas e problemas reais, fundamentadas em referenciais teóricos e diálogos com Paulo Freire, Juan Dias Bordenave, Moacir Gadotti, Howard Gardner e tantos outros, além dos já mencionados Nóvoa, Perrenoud e Peterossi.

Dentre as dez famílias de competências para ensinar, relacionadas por Perrenoud (2000), foram enfatizados no curso principalmente sete:

- Organizar e dirigir situações de aprendizagem - condição necessária para o desenvolvimento de um curso a distância;

- Administrar a progressão das aprendizagens - 0 ambiente virtual de aprendizagem (AVA) proporciona o acompanhamento de cada cursista em relação a sua aprendizagem, inclusive com auto avaliações ao término de cada disciplina;

- Envolver os alunos em suas aprendizagens e seu trabalho - aspecto fortemente considerado no curso, com fóruns de debates e fóruns de produção sempre focados no trabalho do educador;

- Trabalhar em equipe - atividades desenvolvidas em grupo (inclusive avaliações) e situações de aprendizagem colaborativa sempre presentes nos fóruns de debates e de produção;

- Utilizar novas tecnologias - este foi um aspecto que impactou positivamente os cursistas, uma vez que as atividades são vinculadas a instrumentos e programas tecnológicos, possíveis de serem utilizados na prática docente em sala de aula;

- Enfrentar os deveres e os dilemas éticos da profissão - presente nos fóruns e discussões, estimulados pelos tutores;

- Administrar sua própria formação continuada - novamente, atitude indispensável em um curso a distância, desenvolvido concomitantemente com os fazeres de professor, gestor de escola, pai ou mãe, profissional atuante no mercado de 
trabalho, entre outras demandas.

A organização curricular teve como fundamentos os objetivos do curso:

- Contribuir para o aperfeiçoamento de professores das escolas técnicas no atendimento das demandas de educação profissional de jovens e adultos na modalidade EJA.

- Contribuir para o desenvolvimento e aperfeiçoamento de estratégias educacionais e metodologias de ensino-aprendizagem específicas para atuação na educação profissional integrada ao ensino médio.

- Sensibilizar os professores para questões relativas à responsabilidade social, formação profissional e inclusão de jovens e adultos no mundo do trabalho.

O currículo do curso foi, assim, organizado em cinco disciplinas de 40 horas, sendo 8 horas presenciais e 32 à distância. O Trabalho de Conclusão de Curso (TCC) consistiu em um artigo acadêmico sobre educação de jovens e adultos, com abordagens que variaram de políticas públicas a histórias de vida, passando por legislação, metodologias, avaliações, entre outras.

\section{Quadro 1 - Estrutura curricular do curso.}

\begin{tabular}{|c|c|c|c|c|}
\hline \\
\hline \multicolumn{5}{|c|}{\begin{tabular}{|l|l|l}
\multicolumn{2}{|l|}{ Ensino e Aprendizagem na Educação de Jovens e Adultos } \\
Disciplinas & Carga HorárialCarga Horária
\end{tabular}} \\
\hline & Presencial & Distância & Total & \\
\hline Educação e Trabalho & 8 & 32 & 40 & \\
\hline $\begin{array}{l}\text { Ensino e Aprendizagem de } \\
\text { Jovens e Adultos }\end{array}$ & & 32 & 40 & \\
\hline $\begin{array}{l}\text { Planejamento e Práticas de } \\
\text { Ensino para Jovens e Adultos }\end{array}$ & & 32 & 40 & \\
\hline $\begin{array}{l}\text { Avaliação da Aprendizagem de } \\
\text { Jovens e Adultos }\end{array}$ & & 32 & 40 & \\
\hline $\begin{array}{l}\text { Metodologia da Pesquisa } \\
\text { Científica e TCC }\end{array}$ & & 32 & 40 & \\
\hline \multicolumn{3}{|l|}{ Carga Horária Total Presencial } & $40 \mathrm{~h}$ & \\
\hline \multicolumn{3}{|c|}{ Carga Horária Total de Atividades em EaD } & $160 \mathrm{~h}$ & \\
\hline \multicolumn{3}{|l|}{ Carga Horária Total do Curso } & $200 \mathrm{~h}$ & \\
\hline
\end{tabular}

Fonte: Plano de Curso, São Paulo: Centro Paula Souza. 2013 
As atividades presenciais aconteceram em cinco encontros presenciais com pautas distintas e convidados para palestras sobre temas relevantes para o contexto, muitos deles indicados pelos cursistas. Foram também realizadas nesses momentos as avaliações presenciais obrigatórias previstas em legislação (Art. 1ำ, Parágrafo $1^{\circ}$ da Lei 5622/2005) e as apresentações de TCC.

As atividades desenvolvidas à distância foram organizadas por professores denominados de professores conteudistas, selecionados pela sua experiência em educação profissional e conhecimentos na elaboração de material didático on line. Cada disciplina foi dividida em quatro semanas, cada semana sempre com uma atividade de fórum de debates e uma atividade de produção.

O Trabalho de Conclusão de Curso integrou a disciplina Metodologias de Pesquisa e TCC, consolidado em um artigo sobre o tema Educação de Jovens e Adultos.

Os cursistas, autores dos artigos, tiveram oportunidade de submeter seus artigos para publicação na revista Perspectiv@s: um novo olhar para a educação de jovens e adultos[4], bem como em outros veículos de divulgação, simpósios e seminários, extrapolando assim os limites do curso propriamente dito.

Cabe destacar que a proposta do curso, de estimular a aprendizagem colaborativa, foi possibilitada pela postagem das produções dos cursistas nos fóruns de produção e, portanto socializadas, ampliando o espaço de compartilhamento e debates.

Cada turma, de vinte a 22 cursistas cada uma, foi acompanhada por um tutor e um orientador de TCC, nas atividades on line.

O corpo docente foi composto por educadores com pós-graduação, entre especialistas, mestres e doutores, sendo a equipe composta por coordenador, professores conteudistas, tutores, orientadores de TCC e suporte técnico.

Além do material disponibilizado no AVA, também foi produzido um livro base, Formação de Jovens e Adultos- $(\mathrm{Re})$ construindo a prática pedagógica, entregue aos cursistas impresso.

Pelo caráter inovador do curso no Centro Paula Souza, instituição conhecida e reconhecida pelos cursos oferecidos presencialmente, houve um permanente 
acompanhamento por parte da equipe quanto ao grau de satisfação dos cursistas e as suas dificuldades, seja pelos fóruns no AVA, seja nos depoimentos presenciais, ou seja através dos questionários proporcionados ao fim de cada curso e as manifestações nos fóruns de fechamento.

A auto avaliação foi parte do curso, disponibilizado ao fim de cada disciplina e discutido globalmente nos encontros presenciais.

\section{RESULTADOS}

Os profissionais da educação de cursos técnicos deparam-se com dois desafios específicos: o primeiro, pelo seu público, composto em boa parte de adultos, e destes, boa parte retornando à escola depois de um período considerável fora dela; e o segundo, pelas exigências tecnológicas que colocam as práticas tradicionais em cheque.

O curso ora apresentado não apresenta fórmulas mágicas, ou soluções para tais desafios. Procura, no entanto, de uma forma coletiva, estimular a reflexão, o debate e a troca de experiências, resultando em práticas possíveis de adaptação, multiplicação e socialização.

Como mencionado anteriormente, o curso é integrante do Programa Brasil Profissionalizado, num trabalho conjunto entre a Unidade de Pós Graduação, Pesquisa e Extensão e a Unidade de Ensino Médio e Técnico do Centro Paula Souza. Foram realizadas, até o momento (maio de 2018) sete edições do curso, com oferta de 160 vagas por edição, conforme detalhamento na tabela 1.

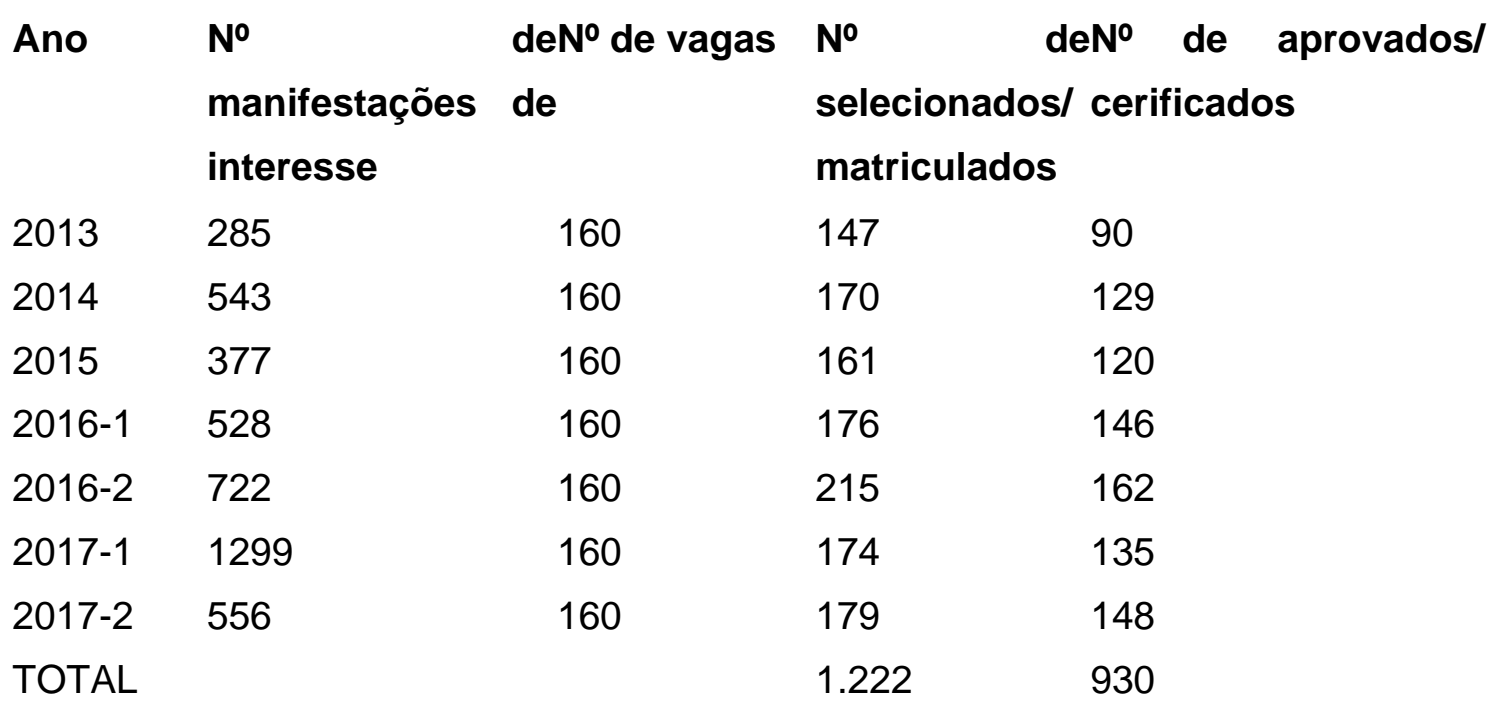


Tabela 1 - Dados numéricos de manifestações de interesse, inscrições, vagas, matrículas e concluintes.

Em relação ao grau de satisfação dos cursistas, foram realizadas pesquisas ao final de cada curso, estando apresentados os dados consolidados de 6 turmas: de 2013 à $1^{\text {a }}$ turma de 2017. Os dados da última turma (2017-2) ainda estão em fase de finalização.

A adoção de ferramentas tecnológicas variadas, como infográficos, histórias em quadrinhos, produção de vídeo, produção de revista eletrônica, uso de padlet e outras foram pontos fortes mencionados pelos respondentes, nas questões discursivas, ressaltando o interesse em aplicá-las em sala de aula.

Foram realizadas perguntas relativas às disciplinas, sobre as atividades e conteúdos de cada uma e os dados apresentados demonstram a predominância, nas manifestações, que a porcentagem de respostas em "Muito bom" e "Bom" sempre ultrapassaram 90\%: da qualidade do curso, do ponto de vista dos cursistas, conforme a tabela abaico.

\section{Disciplinas}

Educação e Trabalho

Ensino e Aprendizagem na Educação de Jovens e Adultos

Planejamento e Práticas de Ensino

Avaliação da Aprendizagem de Jovens e Adultos

$\begin{array}{ll}\text { Muito Bom (\%) } & \text { Bom (\%) } \\ 65,95 & 31,41 \\ 66,12 & 30,83 \\ 69,45 & 28,11 \\ 68,86 & 26,81\end{array}$

Tabela 2 - Avaliação dos cursistas quanto às disciplinas no período de 2013 a 2017-1

O curso apresentado ainda terá continuidade por mais duas edições, dentro do Programa Brasil Profissionalizado, tendo em vista o alto número de manifestações de interesse a cada edição oferecida.

A demanda por formação continuada é constante, e a mediação por computador, através da plataforma Moodle, revelou-se um marco diferencial. sendo desejável que, em condições pós Programa, ainda permaneça como dos componentes de capacitação da instituição.

\section{REFERÊNCIAS}


CNE - Conselho Nacional de Educação. Resolução CNE/CP no 02/2015. Define as Diretrizes Curriculares Nacionais para a formação inicial em nível superior e para formação continuada. Brasília: CNE, 2015

MATHIEU, E.R.O. BELEZIA, E.C. Formação de Jovens e Adultos- (Re)construindo a prática pedagógica. São Paulo: Centro Paula Souza, 2013.

NOVOA, Antonio. Para uma formação de professores construída dentro da profissão. Disponível em www.revistaeducaion.educacion.es/re350/re350_09por.pdf. Acesso em 10 de maio de 2018.

PERRENOUD, Philipp. 10 Novas competências para ensinar. Porto Alegre: Artmed Editora. 2000.

PETEROSSI, Helena Gemignani; MENINO, Sergio Eugenio. A formação do formador. Coleção Fundamentos e Práticas em Educação Profissional e Tecnológica; v.10. São Paulo: Centro Paula Souza, 2017.

[1] Programa Brasil Profissionalizado: Iniciativa do Programa Nacional de Acesso ao Ensino Técnico e Emprego (Pronatec) busca o fortalecimento do ensino médio integrado à educação profissional nas redes estaduais de educação profissional. http://portal.mec.gov.br/brasil-profissionalizado

[2] O Programa de Formação Pedagógica é oferecido hoje com 1000 horas, conforme determinado pela Resolução e Parecer CNE no 02/2005)

[3] EPT - Educação Profissional e Tecnológica

[4] Perspectiv@s: um novo olhar para a educação de jovens e adultos. Revista do Centro Paula Souza com a finalidade de divulgar pesquisas e experiências sobre educação de jovens e adultos em seus mais diversos aspectos e dimensões. Encontrase em sua 4ª Edição (2018). ISSN 2446-7677. 